\title{
Field-scale modeling of microbially induced calcite precipitation
}

\section{Authors: Alfred B. Cunningham, H. Class, A. Ebigbo, Robin Gerlach, Adrienne J. Phillips, Johanna Hommel}

The final publication is available at Springer via https://doi.org/10.1007/s10596-018-9797-6.

Cunningham, Alfred B., H. Class, A. Ebigbo, Robin Gerlach, Adrienne J. Phillips, Johanna Hommel, "Field-scale modeling of microbially induced calcite precipitation," Computational Geosciences, November 2018, 1-16. doi: 10.1007/s10596-018-9797-6. 


\title{
Field-scale modeling of microbially induced calcite precipitation
}

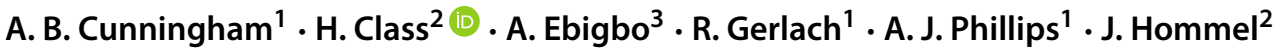

\begin{abstract}
The biogeochemical process known as microbially induced calcite precipitation (MICP) is being investigated for engineering and material science applications. To model MICP process behavior in porous media, computational simulators must couple flow, transport, and relevant biogeochemical reactions. Changes in media porosity and permeability due to biomass growth and calcite precipitation, as well as their effects on one another must be considered. A comprehensive Darcy-scale model has been developed by Ebigbo et al. (Water Resour. Res. 48(7), W07519, 2012) and Hommel et al. (Water Resour. Res. 51, 3695$3715,2015)$ and validated at different scales of observation using laboratory experimental systems at the Center for Biofilm Engineering (CBE), Montana State University (MSU). This investigation clearly demonstrates that a close synergy between laboratory experimentation at different scales and corresponding simulation model development is necessary to advance MICP application to the field scale. Ultimately, model predictions of MICP sealing of a fractured sandstone formation, located $340.8 \mathrm{~m}$ below ground surface, were made and compared with corresponding field observations. Modeling MICP at the field scale poses special challenges, including choosing a reasonable model-domain size, initial and boundary conditions, and determining the initial distribution of porosity and permeability. In the presented study, model predictions of deposited calcite volume agree favorably with corresponding field observations of increased injection pressure during the MICP fracture sealing test in the field. Results indicate that the current status of our MICP model now allows its use for further subsurface engineering applications, including well-bore cement sealing and certain fracture-related applications in unconventional oil and gas production.
\end{abstract}

Keywords Microbially induced calcite precipitation (MICP) $\cdot$ Permeability modification $\cdot$ Field-scale modeling $\cdot$ Reactive transport

\section{Introduction}

Microbially induced calcite precipitation (MICP) is becoming established as a useful technology for a range of geoscience and engineering applications, as summarized by [59], including amending or improving construction materials, cementing porous media, environmental remediation, and containment of nuclear waste. In the subsurface environment, MICP causes deposition of calcium carbonate, resulting in a reduction of porosity and permeability. For example, MICP minerals deposited in preferential flow paths in fractured porous media, and in the near-well-bore environment can mitigate leakage potential of sequestered carbon dioxide, methane, and well-bore fluids [50, 60]. MICP technology is based on the injection of relatively low-viscosity aqueous solutions which promote calcite precipitation to seal unwanted flow paths, especially in small aperture fractures. MICP therefore compliments traditional high-viscosity sealants (e.g., cement) used to seal unwanted flow paths in the near-well-bore environment.

To better understand and predict MICP process behavior in porous media systems, computational simulators must be developed which couple flow, transport, and biogeochemical reactions. Changes in media porosity and permeability need to be considered and coupled to biomass growth and calcite precipitation. A significant challenge in modeling MICP is that many of the standard staple methodologies 
in reservoir engineering are not applicable. This is because MICP applications are rather short (a few days) singular events and, ideally, many simulations are carried out long before the start of the application to guide the design of the injection strategy and other design parameters of the application. In standard reservoir engineering, a host of data is acquired over time, which can be used to improve the reservoir model over the years of the production from a reservoir. Thus, for a typical MICP application, the amount of data available for modeling is significantly smaller than that for standard reservoir engineering and, additionally, parameters such as formation porosity or permeability will change during MICP, further increasing the difficulty of applying methods such as history matching.

A comprehensive model has been developed by the University of Stuttgart and partners and validated at different scales of observation using laboratory experimental systems at the Center for Biofilm Engineering (CBE), Montana State University (MSU) [18, 19, 34, 35]. Ultimately, model predictions of MICP sealing of a fractured sandstone formation, located $340.8 \mathrm{~m}$ below ground surface, were made and compared with actual field experiments which resulted in virtually complete fracture sealing. Results indicate that, even though parts of the current MICP model are still considered as work in progress, it might now be suitable for other types of important subsurface field-scale applications, including well-bore cement sealing and certain unconventional oil- and gas-related applications. Field experiments in both of these areas are now beginning.

Below, we review briefly the major fundamentals of microbially induced calcite precipitation, while referring, for details, to our previous publications in this field. Subsequently, we summarize the history of the development of our mathematical and numerical model, thereby discussing the different scales and the importance of experimental results for step-wise validation of the model. The core part of this paper is then the presentation of the field demonstration, its modeling, and the discussion of the results of this study. This allows us to draw conclusions on the current state of the model and on perspectives on its application in future work.

\section{MICP fundamentals}

Microbially induced calcite precipitation (MICP) occurs when microbial metabolism alters the surrounding aqueous phase in a way that leads to precipitation of calcite. In this study, we focus on biofilm-based MICP via ureolysis by the bacterium Sporosarcina pasteurii. MICP offers an engineering option that uses controlled biofilm growth to achieve targeted calcite precipitation, which can be employed in various applications [e.g., 40, 59, 70]. In subsurface applications, this process is typically associated with a reduction of porosity and, even more importantly, of permeability [e.g., 17, 22, 52, 75]. For example, Minto et al. [49] show the reduction in permeability also by solving the Navier-Stokes equation on the geometry extracted from $\mathrm{X}$-ray computed tomography of samples before and after MICP treatment. S. pasteurii expresses the enzyme urease that catalyzes the hydrolysis reaction of urea $\left(\mathrm{CO}\left(\mathrm{NH}_{2}\right)_{2}\right)$ into ammonia $\left(\mathrm{NH}_{3}\right)$ and carbon dioxide $\left(\mathrm{CO}_{2}\right)$ [e.g., 1]. Aqueous solutions of ammonia become alkaline. Thus, the ureolysis reaction leads to an increase in alkalinity. This shifts the carbonate balance in an aqueous solution toward higher concentrations of dissolved carbonate $\left(\mathrm{CO}_{3}^{2-}\right)$. Adding calcium $\left(\mathrm{Ca}^{2+}\right)$ to the system then results in the precipitation of calcium carbonate $\left(\mathrm{CaCO}_{3}\right)$.

$$
\mathrm{CO}\left(\mathrm{NH}_{2}\right)_{2}+2 \mathrm{H}_{2} \mathrm{O}+\mathrm{Ca}^{2+} \longrightarrow 2 \mathrm{NH}_{4}^{+}+\mathrm{CaCO}_{3} \downarrow \text {. }
$$

Figure 1 illustrates the main processes governing MICP at the pore scale. Ureolytically active $S$. pasteurii cells are introduced in aqueous suspension. These cells attach to surfaces, take up nutrients, and form a biofilm. As biofilm growth continues, some cells detach and are transported down gradient. A detailed discussion of biofilm processes in porous media appears in [18]. The MICP process continues with the addition of urea which is hydrolyzed, resulting in a $\mathrm{pH}$ increase. Subsequent addition of $\mathrm{Ca}^{2+}$ results in calcium carbonate (calcite) deposition, which, together with the accumulated biofilm, causes a reduction in porosity and permeability of the porous medium.

Figure 2 shows a visual example of calcite deposition resulting from the MICP process. In this example, MICP was applied to seal a horizontal fracture in a $76.2-\mathrm{cm}$ diameter sandstone core as reported by [61]. These mesoscale laboratory experiments provided valuable insights into the formulation of a protocol for the injection of media for MICP, including microbial inoculum, urea, and calcium in order to achieve virtually complete sealing of the fracture

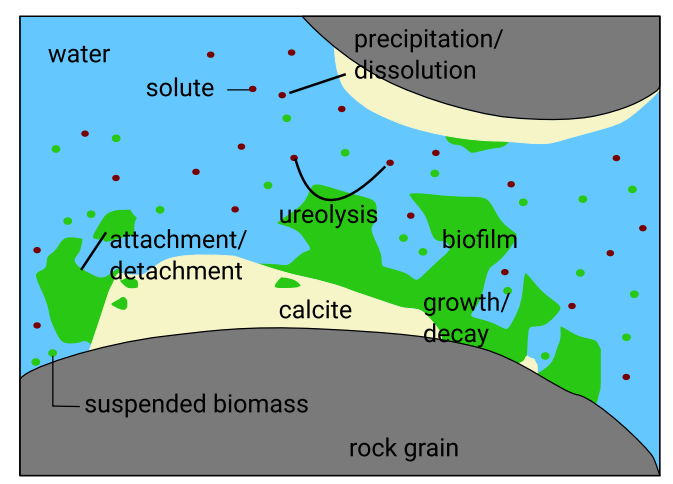

Fig. 1 Schematic view of relevant processes and phases considered in the conceptual MICP model for the field application scenario, modified from [34] 

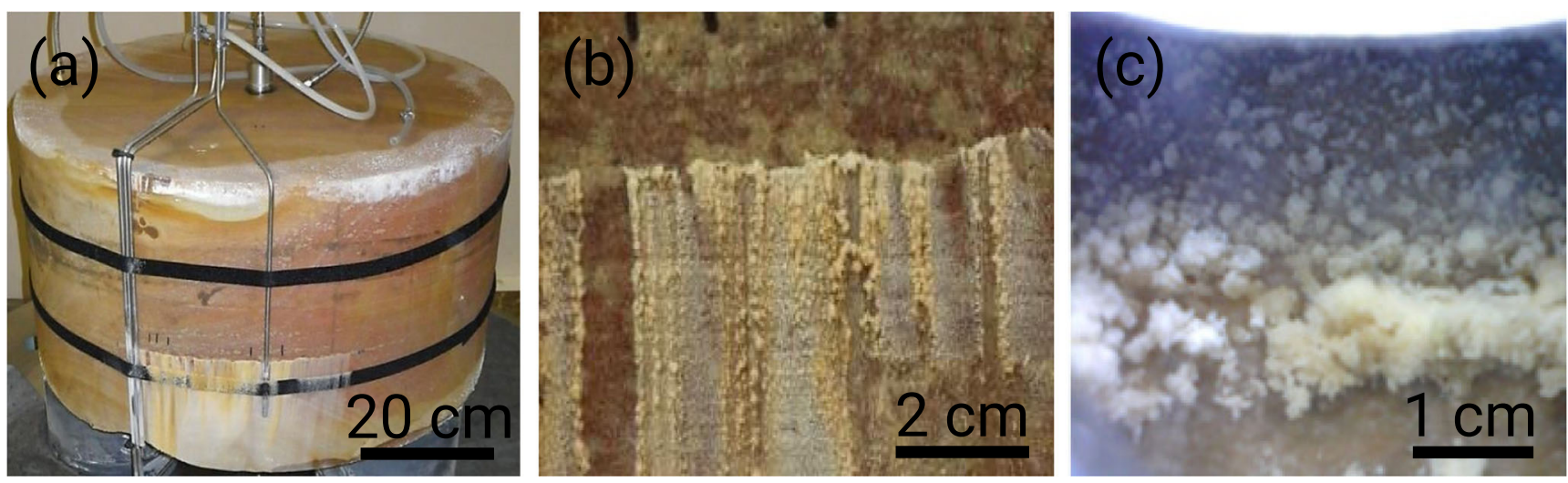

Fig. 2 Precipitates observed from MICP sealing of a 1-mm fracture (33 cm in length) in a 76.2-cm-diameter sandstone core. a, b Precipitates formed in the region of the fracture. $\mathbf{c}$ Precipitates were observed

under radial flow conditions. Modeling of these experiments as an intermediate step before modeling the field-scale application is discussed below in Section 3.3.

\section{Model development}

The major challenge in constructing a predictive model for permeability reduction in the underground with MICP is quantifying the complex interactions between flow, transport, biofilm growth, and reaction kinetics. Any model for MICP, or, more generally, reactive transport, is necessarily a simplification of these processes and their interactions and any new experimental insight into the processes has the potential to improve such models. Thus, there exist a variety of numerical models for reactive transport in porous media which involve microbial activity. Applications found in the literature include the interaction of microbes with the subsurface transport of contaminants, [e.g., 37, 63, 69, 74], microbially enhanced oil recovery [e.g., 44, 53, 54, 72], or biomineralization, of which especially the engineered application of MICP has received considerable attention. Most numerical models for MICP are, similarly to the model used in this study, formulated at the REV scale (or Darcy scale) [e.g., 2, 17, 46, 51, 76-78], while [64] and [80-82] use pore-network and pore-scale models, respectively.

Many models are designed to match some experiments, focusing on the processes of relevance in the particular experiments while neglecting other processes that might be relevant at the field scale. The models presented by [46] and [2] use a complex ureolysis rate equation [23], the same as our initial model [19], and a saturation-state dependent precipitation rate, while neglecting changes in permeability and assuming a constant biomass distribution. This results in a constant ureolytic activity over time for inside the 5.4-cm-diameter stainless steel injection tube. These photographs help visualize the nature of the mineral deposits resulting from the application of MICP to seal fractured porous media

each point. Cuthbert et al. [17] use a first-order kinetic model for ureolysis and model bacterial transport and attachment. However, they simplified the geochemistry by setting the precipitation rate equal to the ureolysis rate. On the other hand, they account for the impact of the calcite precipitated during MICP on hydrodynamics. MichaelisMenten kinetics are used to model the ureolysis rate in [76-78] and, like Cuthbert et al. [17], they assume that the precipitation rate is proportional to the ureolysis rate. The permeability change is accounted for by a Kozeny-Carman relationship, but only calcite is assumed to have an effect. Bacteria are assumed to be homogeneously distributed in [76], while van Wijngaarden et al. [77] account for attachment, detachment, and bacterial transport and van Wijngaarden et al. [78] investigate the effect of various decay and biomass removal rates. For special cases, [76, 77] propose analytical solutions. The kinetic rate equations, in [64] are identical to those used in our modified model [34].

\subsection{Brief presentation of MICP model equations}

The initial model for MICP published by [19] was developed based on the final calcite distribution from four quasi-1D column experiments. It, and its improvement by [34], is to our knowledge the most complex numerical model for MICP that has been published, including a fairly complex solution chemistry, growth, decay, attachment, detachment, transport of biomass, detailed kinetic rate equations for the biomass processes, ureolysis, precipitation and dissolution of calcite, effects of both biofilm and calcite on porosity and permeability, and the possibility to account for two-phase flow. The model is based on standard mass balance equations for each dissolved component (water (w), inorganic carbon (ic), sodium ( $\mathrm{Na})$, chloride $(\mathrm{Cl})$, calcium $(\mathrm{Ca})$, urea $(\mathrm{u})$, ammonium/ammonia (a), substrate $(\mathrm{s})$, oxygen $\left(\mathrm{O}_{2}\right)$, and suspended biomass(sb)) and solid 
phase (biofilm (b) and calcite (c)), using Darcy's law for the phase velocities. Primary variables are the phase pressure, the mole fractions of the components, and the volume fractions of the solid phases.

$$
\begin{gathered}
\sum_{\alpha} \frac{\partial}{\partial t}\left(\phi \rho_{\alpha} x_{\alpha}^{\kappa} S_{\alpha}\right)+\nabla \cdot\left(\rho_{\alpha} x_{\alpha}^{\kappa} \mathbf{v}_{\alpha}\right) \\
-\nabla \cdot\left(\rho_{\alpha} \mathbf{D}_{\mathrm{pm}, \alpha} \nabla x_{\alpha}^{\kappa}\right)=q^{\kappa},
\end{gathered}
$$

here, $t$ is time, $\phi$ porosity, $\rho_{\alpha}, S_{\alpha}$, and $\mathbf{v}_{\alpha}$ the density, saturation, and velocity of phase $\alpha$ respectively, and $x_{\alpha}^{\kappa}$ the mole fraction of component $\kappa$ in phase $\alpha . \mathbf{D}_{\mathrm{pm}, \alpha}$ is the dispersion tensor of phase $\alpha$ in the porous medium, and $q^{\kappa}$ is the source term of component $\kappa$ due to biogeochemical reactions. The mass balances for the solid phases calcite (c) and biofilm (b) contain only a storage and source term since they are immobile:

$\frac{\partial}{\partial t}\left(\phi_{\lambda} \rho_{\lambda}\right)=q^{\lambda}$,

here, $\phi_{\lambda}$ and $\rho_{\lambda}$ are volume fraction and density of the solid phase $\lambda$, and $q^{\lambda}$ is the source term of phase $\lambda$ due to biochemical reactions. The mass balance equations for the transported components (2) and the solid phases (3) are coupled by the component-specific reactive source and sink terms $q^{\kappa}$ and $q^{\lambda}$, which are discussed in detail in [19] and [34]. The porosity is updated by subtracting the solid-phase volume fractions $\phi_{\lambda}$ from the initial porosity $\phi_{0}$ :

$\phi=\phi_{0}-\sum_{i} \phi_{i}=\phi_{0}-\phi_{\mathrm{b}}-\phi_{\mathrm{c}}$.

As both the volume fractions of biofilm $\phi_{\mathrm{b}}$ and calcite $\phi_{\mathrm{c}}$ are assumed to be impermeable, the permeability $K$ can be calculated using the porosity from Eq. 4, without distinguishing between the contribution of each solid. To relate the changes in porosity to the change in permeability, a Verma-Pruess type relation [71] with an exponent of 3 is chosen, reducing the effective porosity by the parameter of the critical porosity $\phi_{\text {crit }}$, at and below which the permeability becomes zero even though a residual porosity persists:

$\frac{K}{K_{0}}=\left[\frac{\left(\phi-\phi_{\text {crit }}\right)}{\left(\phi_{0}-\phi_{\text {crit }}\right)}\right]^{3}$.

The model is implemented in the open-source simulator $\mathrm{DuMu}^{\mathrm{X}}$ (DUNE for Multi-Phase, Component, Scale, Physics, .. .) [24], which is based on DUNE (Distributed and Unified Numerics Environment) which, itself, is an open-source framework for solving partial differential equations [3, 4]. This study uses as discretization methods implicit Euler for time and a fully coupled, vertex-centered finite volume (box) scheme [30] for space. The resulting system of equations is solved using the BiCGStab solver
[73] after being linearized using the Newton-Raphson method. The time stepping is adaptive and the size for each time step is determined by the number of Newton iterations until convergence of the previous time step and its size. In case the Newton-Raphson method does not converge within a maximum number of iterations, the time step is restarted with half the initial time-step size.

A comprehensive discussion of the MICP model, especially the individual reactive source and sink terms, the capability for including a potential second fluid phase, and the treatment of equilibrium dissociation reactions, is given in [19] and [34] (for convenience, we summarize the reactive source and sink terms, the reaction rate equations, the model parameters used, and the initial and boundary conditions in the Appendix).

\subsection{How the model was improved by experiments}

In [34], the MICP model was improved based on new insights regarding the main driving force of the MICP reactions, urea hydrolysis. Experiments with S. pasteurii, the organism mostly used for engineered MICP research and development, allowed us the determination of wholecell ureolysis kinetics parameters [45]. This in turn allowed for the implementation of more appropriate ureolysis rate kinetics in the reactive source and sink terms associated with ureolysis.

Simultaneous to the investigation of the ureolysis kinetics, new column experiments were conducted monitoring $\mathrm{Ca}^{2+}$ and $\mathrm{NH}_{4}^{+}$concentrations at $10-\mathrm{cm}$ intervals along the column over time to provide improved experimental data for recalibration of the model by inverse modeling [34]. This significantly increased the experimental data available for calibration compared to the previous experiments, where only the final amount of calcite along the column was available [19]. The updated and recalibrated model was validated using data of the replicate of the new column experiment, again with $\mathrm{Ca}^{2+}$ and $\mathrm{NH}_{4}^{+}$concentration and final calcite measurements, as well as a previous experiment described in [19, 34]. The improved model proved to be more robust with respect to the medium chemistry, which changed between the experiments reported in [19] and [34], increasing its predictive capabilities. However, the model was, up to that point, almost exclusively validated with data from quasi-1D column experiments with plug-flow conditions. Thus, a comparison between model predictions and experimental data in a full 3D setup with radial flow conditions was conducted before the model was applied to investigate a field-scale scenario. Figure 3 provides a summary of the interaction between laboratory experimentation and model development. 


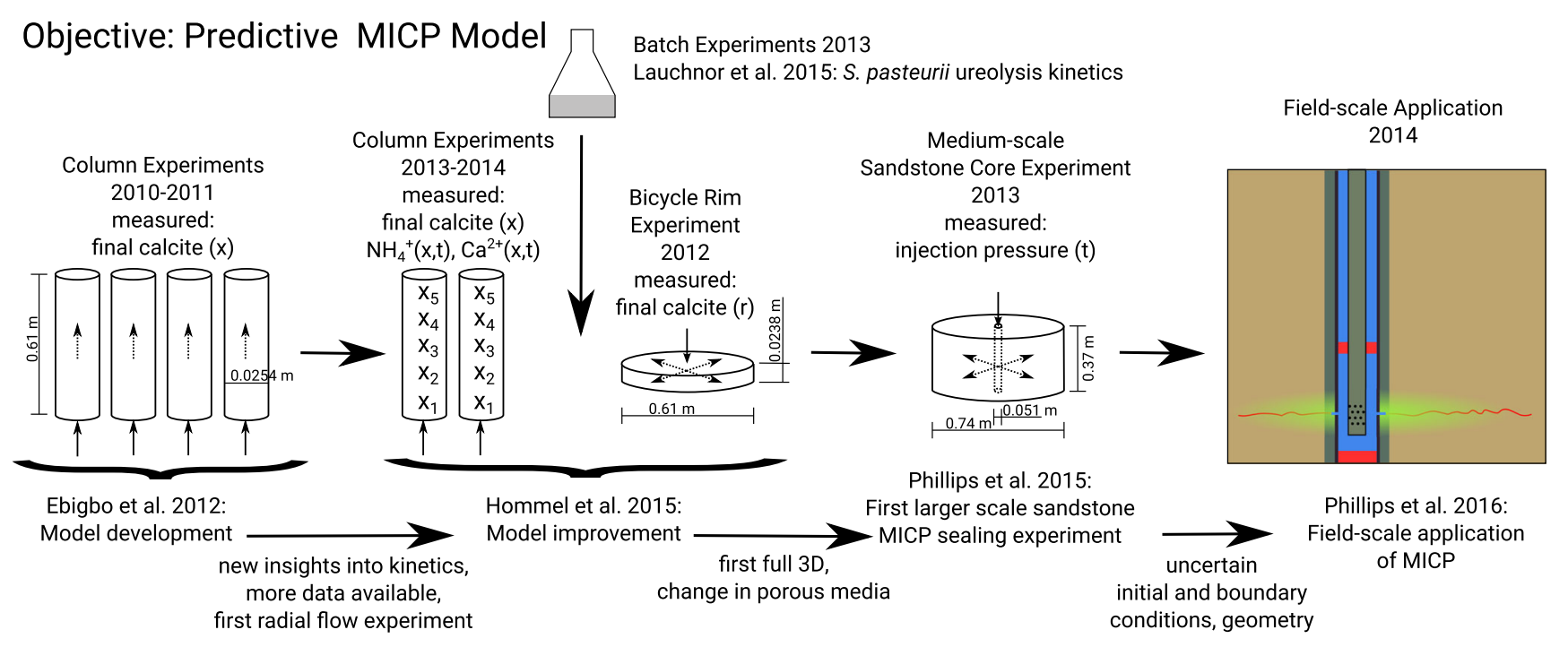

Fig. 3 Model and experiment development involved in preparation for the field-scale application

\subsection{Transition from laboratory to field-relevant applications}

The model published by [19] and [34] was essentially validated using quasi-1D column experimental data and one 2D radial flow data set. Additionally, in all of the previous experiments, the porous medium had been homogeneous sand. Therefore, as the next step toward field application, we investigated the model's capability to predict radial flow in a 3D domain in a field-relevant porous medium (sandstone). To this end, we simulated MICP sealing in the medium-scale sandstone through the experiments by [61] (summarized in Fig. 2), which featured a horizontal fracture and horizontal flow conditions. The model and parameters used were those published in [19], as the simulation was carried out in 2013, before the model was improved and recalibrated by [34] (see Section 3.2). This horizontal sandstone fracture experiment was very similar to the conditions encountered in the MICP field demonstration described in Section 4. The setup and initial and boundary conditions for the simulation were taken from [61]. The boundary conditions are chosen as no-flow conditions except for Dirichlet conditions at the outer radius and the top and the injection at the inner radius according to [61]. The simulation showed that the model was able to simulate 3D domains, although the computational costs are high. The model results (Fig. 4) show preferential biomass accumulation in the high-permeability layer at the bottom of the simulation domain representing the fracture in the sandstone core. This leads to preferential precipitation within this layer, eventually sealing the fracture as also observed in the experiments by [61] summarized in Fig. 2 .
A detailed discussion of the results for this modeling effort is beyond the scope of this article. However, there was good qualitative agreement between simulation results and experimental observations, which increased our confidence that the model could be applied to similar conditions at the field site without significant further modification.

\section{Modeling MICP at the field scale}

A subsurface sandstone fracture-sealing field demonstration was conducted in April 2014. Collaborators on this field-scale demonstration include the Center for Biofilm Engineering at Montana State University (CBE/MSU), Southern Company (SC), the University of Alabama at Birmingham (UAB), Schlumberger Carbon Services (SLB), Shell International Exploration and Production B.V. (Shell), and the University of Stuttgart (Stuttgart). CBE/MSU designed the field demonstration protocol, oversaw testing, and analyzed results. Stuttgart supervised numerical modeling in collaboration with CBE researchers. Southern Company conducted geologic site characterization and obtained rock core samples from the field for laboratory analysis. SC also helped coordinate field operations with Schlumberger. UAB conducted multiple core tests on field and laboratory sandstone rock core samples. Shell assisted in designing the field demonstration and analyzing results. All collaborators actively participated in decision-making and evaluation for each stage of the project. This project integrated expertise from practitioners (SC, SLB, and Shell) with experimental research (MSU/CBE, UAB) and numerical modeling (Stuttgart) to successfully complete the field demonstration 


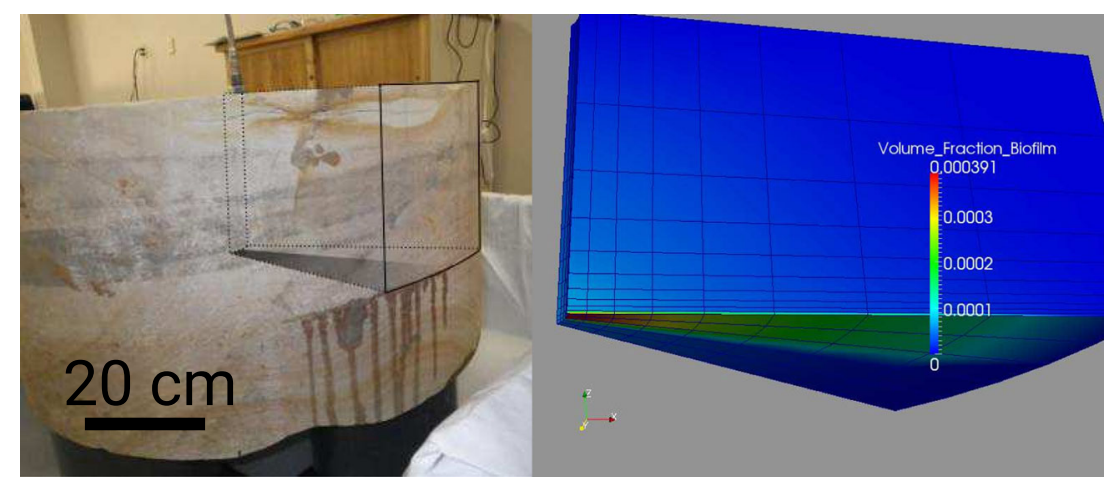

Fig. 4 MICP modeling of the sandstone-core experiment from Fig. 2: (left) picture of the fractured meso-scale core and a sketch of the simulation domain with the shaded area as the highly permeable layer representing the fracture; the darker areas are indicative of fluids exiting

thoroughly evaluating the field injection protocol, field delivery system, and effectiveness of the biomineralization sealing process. Herein, we highlight the role of numerical modeling at Stuttgart.

\subsection{Description of the MICP sealing field demonstration}

Previously reported MICP-related field studies include stimulation of microbial urea hydrolysis in groundwater to enhance calcite precipitation, [27], using MICP to reduce permeability of fractured volcanic rock at a $25-\mathrm{m}$ depth, [17], and precipitation of calcite by indigenous microorganisms to strengthen liquefiable soils, [10]. Another noteworthy large-scale MICP experiment which quantified biomediated ground improvement by ureolysis is reported by [56] The MICP sealing field study discussed herein builds on these previous field-scale studies by demonstrating the use of MICP in fractured sandstone $340.8 \mathrm{~m}$ below ground surface (bgs) using conventional oil-field delivery techniques.

The MICP sealing field demonstration was performed inside a 24.4-cm-diameter well located on the Gorgas Steam Generation facility near Jasper, AL, USA (hereafter referred to as the Gorgas site). The target zone for the sealing experiment was a horizontal sandstone fracture, located $340.8 \mathrm{~m}$ bgs.

The field demonstration involved the following sequence: (1) field-site characterization; (2) fracturing the sandstone formation to develop injectivity; (3) design of a protocol for field injection strategy; (4) injection of microbes, urea, and calcium in the field using conventional oil-field delivery technologies; and (5) assessment of the fracture plugging after treatment. This sequence was described in detail in [62].

Site description Based on a review of the petrophysical well logs for the site prepared by Schlumberger, the Fayette the horizontal fracture. (Right) model prediction of biofilm distribution after 1.16 days of injection. Most of the biofilm is concentrated in the fracture at the front and bottom of the domain

sandstone group at a depth of 338.3 to $341.4 \mathrm{~m}$ bgs was determined to be the best candidate for performing the field demonstration. The Fayette is a sandstone with, at this location, a porosity of approximately $12 \%$ and a permeability of $\sim 1.0856 \times 10^{-14} \mathrm{~m}^{2}(11 \mathrm{mD})$, according to the preapplication petrophysical analysis by Schlumberger. The cement bond log (not shown) indicated good cement across the zone, so good hydraulic isolation was expected. Prior to the actual biomineralization sealing test, a bridge plug was installed in the well at an elevation of $343.5 \mathrm{~m}$ bgs. This plug established the lower boundary of the injection zone for injection of test fluids. The completely cased well was perforated in the target region, 340.7 to $341.1 \mathrm{~m} \mathrm{bgs}$, and a packer was set to isolate the Fayette formation [62].

Preliminary well testing established that the $1.0856 \times$ $10^{-14} \mathrm{~m}^{2}$ permeability of the Fayette sandstone was too low to conduct a meaningful MICP test on the formation itself and, therefore, it was decided to hydraulically fracture the formation in order to increase injectivity. Hydraulic fracturing was carried out by Schlumberger and resulted in the establishment of a single horizontal fracture plane extending radially into the Fayette sandstone located 340.8 $\mathrm{m}$ bgs. This fracture plane was established as the target zone for subsequent MICP sealing activities.

MICP field test The MICP field demonstration involved microbial inoculation of the formation with $S$. pasteurii combined with urea and calcium injections over the course of four days. Several months prior to the field demonstration, multiple scenarios were run with the MICP simulation model considering actual characteristics at the Gorgas site. These modeling results were used to plan the actual injection sequence of MICP components. We also considered well-bore mixing and transport into the formation in such a way as to encourage reaction and calcite precipitation in the formation as opposed to inside the well-bore. This involved determining the schedule and flow rates 
for injecting fluids both during and after bailer injection of MICP components. We also needed assurance that the time needed to develop the MICP seal of the fracture would be no longer than 4 days. The MICP modeling scenarios, together with pre-field-test laboratory experiments, provided an efficient process for screening alternatives which resulted in the "best predicted" field injection strategy. Based on these results, it was possible to estimate quantities of key components such as microbial inoculum, calcium, and urea needed for the field work. This a priori MICP modeling/experimentation effort proved extremely valuable in successfully completing this MICP-based fracture sealing in the field.

During the actual field demonstration, a total of 24 calcium injections and six microbe injections were required over the 4-day period to achieve complete sealing. Conventional oil-field methods were used to deliver the biomineralization components downhole by using an 11.4-1 wireline dump bailer combined with periodic pumping of a brine solution into the fractured formation. The fractured region was considered completely sealed when it was no longer possible to inject fluids into the formation without exceeding the initial formation fracture pressure. On day 3 , around $45 \mathrm{~h}$ after the first injections, a significant decrease in injectivity was observed and the flow rates had to be reduced during the fourth day to avoid exceeding the formation's fracture pressure. Sealing of the fracture with MICP was assessed through (i) the reduction of injectivity, (ii) decrease in pressure decay after well shut in, and (iii) detection of MICP byproducts including calcium carbonate $\left(\mathrm{CaCO}_{3}\right)$ in side-wall cores retrieved from $1.8 \mathrm{~m}$ above the fracture zone. Detailed results of this MICP field demonstration are presented in [62].

\subsection{Model predictions and evaluation}

In this section, two categories of modeling scenarios are discussed. The first category, identified as the 2014 simulations, refers to the modeling done prior to and immediately after the April 2014 field demonstration. The second category, identified as the 2018 simulations, refers to recent modeling done after evaluating the results of the field demonstration. The main difference of the simulations are the sets of parameters used and that the 2018 simulations consider infinite-acting pressure boundary conditions at the outer radius of the simulation domain.

As the model recalibration discussed in [34] was not yet completed at the time of the first modeling study in 2014, the values for some model input parameters differed from those published there. Those parameter values are given in Table 1. All other parameter values are identical to those published in [34]. Thus, in addition to investigating the effect of an improved pressure boundary condition, the 2018 simulations were also aimed at highlighting the impact of the changed set of parameters on the simulation results. No parameters were fitted for the field-scale simulations, as the 2014 simulations were conducted prior to and immediately after the field application, when no data for recalibration were available. Also, for the 2018 simulations, no parameters were fitted specifically for the field-application setup due to the scarcity of field-scale data.

Simulation domains and geometry To address the uncertainty in the extent of the radial fracture, two scenarios were investigated prior to the 2014 field application: the "small" $2.4 \mathrm{~m} \times 2.4 \mathrm{~m}$ (height $\times$ radius) scenario with a radial fracture extent of $1.6 \mathrm{~m}$ and the "large" $8 \mathrm{~m} \times 8 \mathrm{~m}$ scenario with a radial fracture extent of $4 \mathrm{~m}$. Both scenarios were simulated assuming various injection strategies (not shown or discussed here) and the best injection strategy was chosen to be used for the actual field test. For the recent simulations in 2018, the "large" scenario was extended to a radius of $50 \mathrm{~m}$. As the vertical extent of the MICP sealing into the formation was part of the research question, it was necessary to use a 3D model and therefore not possible to reduce the domain to a $2 \mathrm{D}$ fracture plane. The simulation domains were constructed assuming radial symmetry with the domain height as well as the radial extent adjusted to the radial extent of the fracture, resulting in a height and radius of $2.4 \mathrm{~m}$ for the small and $8 \mathrm{~m}$ for the large scenario (see Fig. 5). For each scenario, the fracture is approximated as a 5 -cm-thick highly permeable layer in the vertical center of the simulation domain. Within this layer and adjacent to it, the resolution in vertical direction is chosen to $\Delta z=1 \mathrm{~cm}$.

The representative fracture-layer permeability $K_{\text {frac }}=$ $1.645 \times 10^{-12} \mathrm{~m}^{2}$ was estimated using the cubic law and

Table 1 Parameters used in the 2014 pre-application simulations which differ from the final calibration values published by [34]

\begin{tabular}{|c|c|c|c|c|}
\hline Parameter & $c_{\mathrm{a}, 1}$ & $c_{\mathrm{a}, 2}$ & $\rho_{\text {bio }}$ & $k_{\mathrm{ub}}$ \\
\hline Units & {$[1 / \mathrm{s}]$} & {$[1 / \mathrm{s}]$} & {$\left[\mathrm{kg} / \mathrm{m}^{3}\right]$} & [ $\left.\mathrm{kg}_{\text {urease }} / \mathrm{kg}_{\text {bio }}\right]$ \\
\hline Brief description & $\begin{array}{l}\text { Unspecific biomass } \\
\text { attachment coefficient }\end{array}$ & $\begin{array}{l}\text { Biomass attachment coef- } \\
\text { ficient to existing biofilm }\end{array}$ & Biofilm dry density & $\begin{array}{l}\text { Urease content of } \\
\text { biomass }\end{array}$ \\
\hline 2014 pre-application & $1.5 \times 10^{-5}$ & $5 \times 10^{-6}$ & 10 & $1 \times 10^{-2}$ \\
\hline [34] & $8.3753 \times 10^{-8}$ & $8.5114 \times 10^{-7}$ & 6.9 & $3.81 \times 10^{-4}$ \\
\hline
\end{tabular}




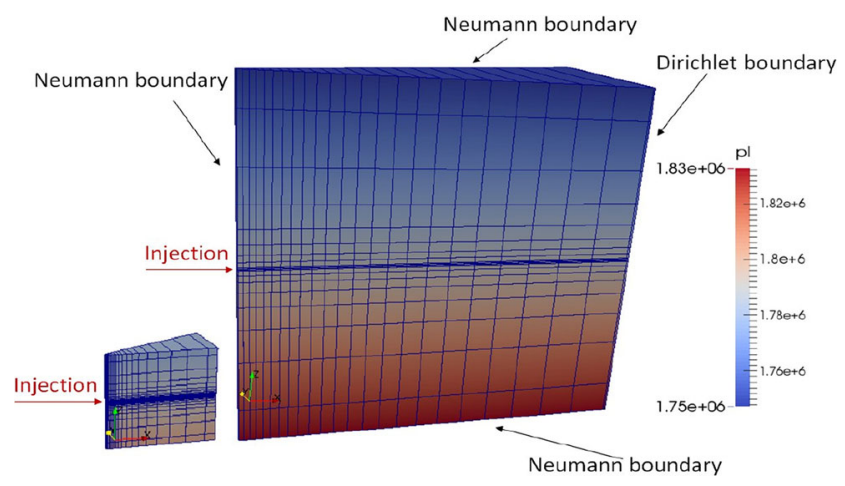

Fig. 5 Sketch of the grid for the $2.4 \mathrm{~m} \times 2.4 \mathrm{~m}$ and the $8 \mathrm{~m} \times 8 \mathrm{~m}$ and the initial pressure (in $\mathrm{Pa}$ ) as well as the boundary conditions used for the 2014 simulations

comparing single-phase-flow simulation results for the large scenario to the data from the field-site pumping tests conducted by Schlumberger Carbon Services prior to the field application. The fracture aperture used was $a=$ $100 \mu \mathrm{m}$, as estimated by Schlumberger Carbon Services resulting in a permeability according to the cubic law of $K_{\text {cubic }}=\frac{a^{2}}{12}=8.3 \times 10^{-10} \mathrm{~m}^{2}[36]$. Aperture-weighted averaging of $K_{\text {cubic }}$ and the formation permeability of $K=1.0856 \times 10^{-14} \mathrm{~m}^{2}$ over a total chosen fracturelayer thickness of $5 \mathrm{~cm}$ results in an apparent fracture-layer permeability of $K_{\text {frac,app }}=1.667 \times 10^{-12} \mathrm{~m}^{2}$, which was then reduced to $K_{\text {frac }}=1.645 \times 10^{-12} \mathrm{~m}^{2}$ to match the preapplication, post-fracturing pumping test data on the large simulation domain.

The fracture-layer porosity is assumed to be identical to the formation porosity of $12 \%$, as the fracture-aperture estimates by Schlumberger Carbon Services were much smaller $(a=100 \mu \mathrm{m})$ than the vertical resolution used for the fracture layer $(1 \mathrm{~cm})$. The critical porosity, at which
$K=0$, in the porosity-permeability relation is estimated to be $\phi_{\text {crit }}=0.1$, based on the $\phi_{\text {crit }}$ previously fitted for sandstone cores of similar sandstones with comparable initial permeability [33]. The computational grid is refined towards the well and around the fracture (see Fig. 5). The initial conditions are chosen as hydrostatic pressure distribution with a pressure of $1.79 \times 10^{6} \mathrm{~Pa}$ for the simulations done prior to the field demonstration (2014) and $3.34 \times 10^{6} \mathrm{~Pa}$ for the recent (2018) simulations of the field application at the vertical center of the domain. The latter value is higher because it accounts for the filling of the well with water up to the surface.

The initial concentrations (in mole fractions) of the various chemical species are zero except for inorganic carbon $x_{\mathrm{ic}}=1.79 \times 10^{-7}$ as well as $\mathrm{Na}^{+}$and $\mathrm{Cl}^{-}$, which are both set to $x_{\mathrm{Na}}=x_{\mathrm{Cl}}=0.007$ to match the formation salinity of $24 \mathrm{~g} / \mathrm{l}$ reported in [16]. All other components are assumed not to be present initially. The boundary conditions are set to no-flow boundaries, except for the injection into the fracture layer at the inner radius and a Dirichlet boundary condition for the entire outer radius, which is set to the initial values, except for the pressure in the 2018 simulations. For the 2018 simulations of the actual field application, a simple flow simulation, without component transport and reactions, in a large, 10$\mathrm{km}$ radius domain is used to determine the time-dependent pressure for the Dirichlet boundary condition at the outer radius of the smaller simulation domain for the MICP simulations. Additionally, the simulation domain for MICP was increased to a 50-m radius, keeping the height at $8 \mathrm{~m}$, to capture a more significant portion of the region with high pressure gradients. This is necessary as the pressure signal will obviously propagate much further than the outer radius of the grids used for the simulations in 2014. However, much larger grids than those used are not practical for the
Fig. 6 Permeability along the radius through the high-permeability layer as predicted by simulations for various grids, domain sizes, and injection strategies. Note that the initial permeability on the left is only shown for the "large" 8 $\mathrm{m} \times 8 \mathrm{~m}$ scenario and that for the "small" $2.4 \mathrm{~m} \times 2.4 \mathrm{~m}$ scenario, the initial high permeability only extends to a radius of $1.6 \mathrm{~m}$

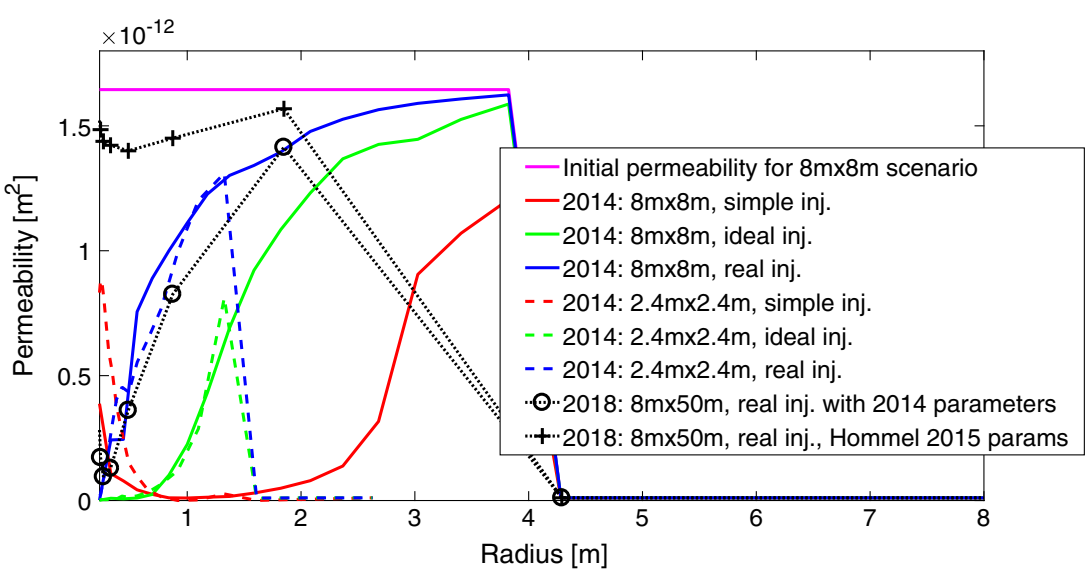


MICP simulations due to the complexity and associated computational time of the model, which would, on larger grids, result in impractically long simulation times.

Model predictions First, the modeled injection strategies and the times of the simulations relative to the field experiment are discussed. We distinguish between the pre-experiment simulations, done in 2014, and the post-experiment simulations, done in 2014 immediately after the field experiment and in 2018. The pre-experiment simulations examined the influence of the injection strategies, "simple" and "ideal," the size of the domain, "small" and "large," and radial extent of the fracture, on the simulation results. The post-experiment simulations focused on reproducing the field experiment using the exact ("real") injection strategy and, additionally for the 2018 simulation, investigating the effect of the model recalibration by [34] and the outer radius Dirichlet boundary condition on the results.

Two injection strategies were considered during the planning of the 2014 field experiment, one with a low number of injections of long duration each, referred to in the following as the "simple" injection strategy, and one with a high number of short injections, referred to in the following as the "ideal" injection strategy. The latter injection strategy consisted of 7 cell inoculation and 34 calcium-rich injections, alternating with no-flow periods after the injections allowing for bacterial growth and attachment or reaction. Inoculations were done in the beginning and then prior to overnight no-flow periods and after five of the ten daily calcium-rich injections. Calcium- and cell-free media were injected for a short period before reinoculating to prevent clogging of the immediate vicinity of the well. This injection strategy was chosen to be applied in the field (see the description in Section 4.1), as the model predictions suggested sufficient permeability reduction (see Fig. 6), and because the more frequent and faster injections would reduce the risk of unwanted precipitation within the well-bore. A slightly changed strategy was actually applied in the field. This will be referred to as the "real" injection strategy. It was modeled immediately after the field experiment in 2014 and, again, after analyzing the field measurements in 2018. It is similar to the "ideal" strategy but includes sampling and technical problems encountered during the field demonstration as well as decreasing injection rates towards the end of the test. The results for permeability predictions of the model for the three injection strategies simulated in 2014 and the "real" injection strategy simulated in 2018 are shown in Fig. 6. The "simple" injection strategy results in almost complete plugging of the high permeability region. For the "ideal" and "real" injection strategies, permeability is reduced mostly in the first $0.5 \mathrm{~m}$ to $1 \mathrm{~m}$ of the domain, independent of the size of the domain used, when using the 2014 parameter set (see Table 1). Using the best-fit values published by [34] (Table 1) leads to much less permeability reduction, as much less precipitates are predicted to form (see Fig. 7).

The experimental data that can be compared to model results are limited to the recorded injection pressure and a few side-wall cores due to the depth of $340.8 \mathrm{~m}$ bgs. Thus, it is difficult to conclude which domain size, boundary conditions, and parameter sets are most accurate. The sensitivity of the model to the estimated formation porosity and permeability, to the assumed fracture-layer porosity and permeability, and to the assumed critical porosity has not been investigated.

A comparison of the "small" and the "large" scenario simulated in 2014 indicates that large simulation domains might only be necessary to investigate the uncertainty in the initial geometry, e.g., extent of the high-permeability layer. Large domains might not be necessary to model MICP for a fixed geometry as the results of both scenarios are quite similar as long as the radius of the domain is smaller than the extent of the "small" scenario's high-permeability layer (see Fig. 6), when using identical parameter sets. Equally, even when using the further increased domain $(8 \mathrm{~m} \times 50$ $\mathrm{m}$ ) and a dynamic pressure boundary condition in the 2018 simulations, the results for the biomass (not shown) and calcite distribution do not change significantly compared to the simulations of 2014 with a fixed equilibrium hydrostatic pressure boundary condition, when using identical parameters (see Fig. 7). This is a result of the source and sink terms in the model for MICP being almost independent of the absolute value of the pressure. The pressure influences the reaction terms only indirectly by the minor pressure dependency of the apparent dissociation constants (see [34]). Only the pressure gradient has a significant influence on the detachment rate of biomass, but as the injection is treated

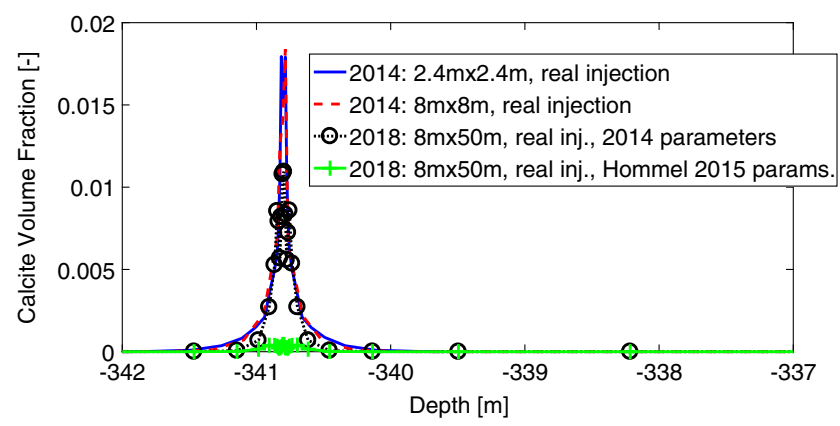

Fig. 7 Calcite volume fractions at the inner boundary over depth predicted by simulations on various simulation domain sizes. The high-permeability layer into which fluids are injected is situated at $340.8 \mathrm{~m}$ below surface 
as a Neumann boundary, the near-well-bore pressure gradients are independent of the absolute pressure values set at the Dirichlet boundary condition. The simulation results using the planned ("ideal") injection strategy match the field-application results very well, as they predict plugging after $25 \mathrm{Ca}^{2+}$-rich and 6 biomass injections, and also the "real" injection strategy results in a significant permeability reduction (see Fig. 6). Although both biofilm and calcite are assumed to be impermeable, most of the permeability reduction is due to calcite, which, for the "real" injection strategy reaches higher volume fractions $\left(\phi_{\mathrm{c}, \max } \approx 0.02\right)$ compared to the small volume fraction of biofilm $\left(\phi_{\mathrm{b}, \max } \approx 0.0006\right)$. However, we have to note that using the updated parameter values from [34] that were the best to model the calibration column experiments did not improve the agreement between the model results and the field-scale experiment. On the contrary, biofilm and calcite volume fractions are reduced and no significant plugging is predicted by the model using this parameter set (see Figs. 6 and 7).

It is currently not possible to explicitly verify the simulation results for permeability shown in Fig. 6 due to the lack of data. However, side-wall cores, discussed in Section 4.1, collected a year after the field application $1.8 \mathrm{~m}$ above the injection show biomineralized calcite. This compares quite well with the model results of $\mathrm{CaCO}_{3}$ reaching roughly $1 \mathrm{~m}$ above and below the fracture layer (see Fig. 7), especially, when considering that the scenarios investigated assume, except for the high-permeability layer fracture layer, homogeneous initial porosity and permeability without any vertical preferential flow paths. Similarly to calcite, most biomass (not shown here) is concentrated in the highpermeability layer, as in the medium-scale sandstone core in Fig. 4.

Another parameter that can be compared between the field application and simulation results is the injection pressure, which is the downhole pressure at the elevation of the entrance to the fracture. In the simulation, the injection pressure is strongly influenced by the Dirichlet pressure boundary condition set at the outer radius. Figure 8 shows the pressure increase due to the total of 30 individual pulses of inoculum or mineralization medium injection and the pressure decrease after each injection. Also, due to the permeability decrease after $40 \mathrm{~h}$, the injection pressure does not relax as fast as during the previous injections, leading to the increase in injection pressure, which was also observed in the field [62]. The simulation results, even the recent 2018, with dynamic pressure boundary conditions, are still significantly lower than the maximum pressures measured in the field which were measured to be between $\approx 7 \times 10^{6}$ and $\approx 8 \times 10^{6} \mathrm{~Pa}$ (not shown in Fig. 8). Unfortunately, the pressure measurements in

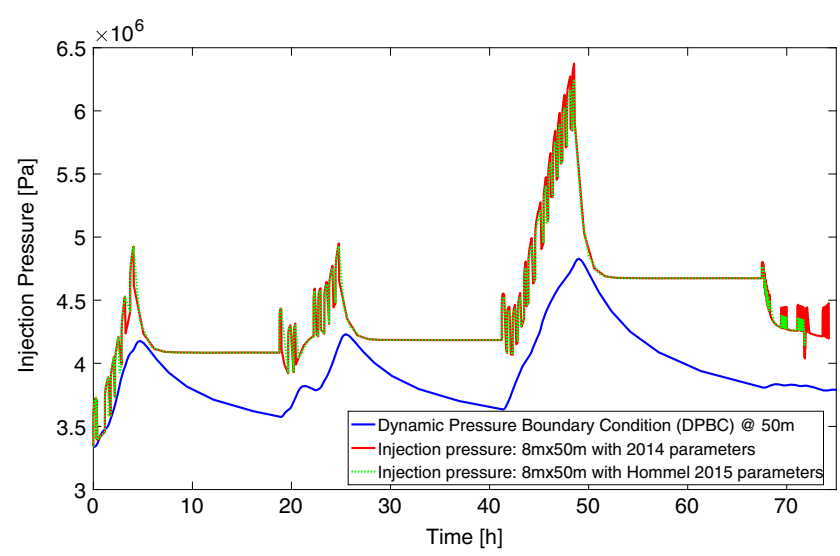

Fig. 8 Injection pressures as predicted by the model for the "real" injection strategy compared to each other and the dynamic pressure boundary condition pressures set for the 2018 simulations. The dynamic pressure set as Dirichlet boundary condition was determined from simple injection simulations on the same geometry, but a radial extent of $10 \mathrm{~km}$

the field focused mainly on the maximum pressure peaks during each of the individual injections to avoid potential for damaging the equipment used or refracturing the formation. No continuous pressure measurements were recorded which would be comparable with the simulation data. The general trend in the pressures is matched qualitatively with the gradual increase in pressures as the application proceeded and a pronounced pressure peak at the end of the third day. The difference between the 2014 and 2018 simulations highlights the difficulty of choosing realistic pressure boundary conditions for such field application simulations. However, the pressure has no significant influence on the calculated volume fractions of biofilm (not shown here) or calcite and, therefore, on porosity and permeability (see Figs. 6 and 7) as the (bio-)geochemical source and sink terms are not pressure-dependent except for the apparent dissociation constants (see [34]). Thus, the effect of pressure on the simulation results is almost completely limited to the hydraulic part of the model, and not the absolute value of the pressure is relevant, but rather the injection-dependent pressure gradient.

While the data do not allow an accurate quantitative comparison with the simulation results, there is still encouraging qualitative agreement between simulation results and corresponding field-scale observation of three key system responses. First, we determined that the model prediction of 25 calcium-rich pulses necessary to achieve fracture plugging compared very well with the field observation of 24 calcium-rich pulses. Also, side-wall coring revealed that calcite deposits extended roughly $1 \mathrm{~m}$ above and below the fracture layer, which compares favorably 
with model results. In addition, the profile of simulated downhole injection pressure compared favorably during periods where actual downhole pressure was measured, especially during the third day when clogging began to occur in the field (Section 4.1).

\section{Conclusions}

\subsection{The state of the MICP model so far}

The long-term goal of this research is to develop biomineralization-based technologies for sealing preferential flow pathways near well-bores and other applications of permeability modification in the subsurface. The history of development of our MICP model clearly demonstrates that a close synergy between laboratory experimentation at different scales and corresponding simulation model development is highly desirable to realize a successful application at the field scale. Joint experimental investigations and model development as discussed in [19] and [34] has now taken an enormous step towards real field applications. This brings along new challenges. One issue is that the best-fit parameters from [34] result in only minor precipitation for the field-test setup, while the estimated parameter values used in the 2014 simulations (see Table 1), predict significant clogging. However, both the porous medium and the flow field are completely different between the field-test and the calibration setup of [34]. It is difficult to determine exactly why the change in conditions results in another set of parameters seemingly better adapted than the laboratory best-fit parameters. However, it has to be noted that the values of the fitting parameters of the model are strongly correlated [34], which would require a whole set of well-controlled experiments in the relevant porous media and at various scales with more measurements of different kinds, all tailored to fulfill the demands of the model to identify a unique set of best-fit parameters. This is clearly our vision for future studies.

Inconsistencies between laboratory and field scale could also possibly arise from local, sub-REV-scale heterogeneities in the field which could result in apparently different kinetics at the modeled resolution as discussed in [11], or such discrepancies might be caused by processes, which have behavior at the laboratory scale that is different than at the field scale, or different behaviors in different porous media. The effects from different porous media, e.g., from different pore-size distributions, different pore morphologies, or chemical compositions, might be addressed by rigorous upscaling of MICP from the pore scale to larger scales. This could possibly lead to upscaled porous mediumdependent parameterizations of the processes for MICP similar to the studies of, e.g., [7-9, 31, 43, 55, 58]. Nonetheless, at the field scale, there will always be an insufficient amount of information for upscaling. Hence, some degree of parameter fitting is always to be expected. Rigorous upscaling is important to obtain the appropriate functional form of constitutive relationships.

What we consider important for investigating the upscaling of MICP processes between the laboratory and the field scale is a close cooperation between experimentalists and modelers, as demonstrated in this study and others, e.g., by [51], and, very importantly, more well-controlled largerscale experiments such as those conducted by [56]. A second, equally important, issue is that information on the setup is drastically reduced compared to well-controlled laboratory work, thus complicating determination of correct initial and boundary conditions or other properties of the simulation setup such as the initial distribution of porosity and permeability. Due to this uncertainty in the parameters, it is important to reduce the computational effort of the model for future applications to enable statistical assessment of the effects of the unknown porosity and permeability and, probably to some degree, their heterogeneous distribution. There are various means to achieve this, e.g., local grid refinement, improving the time stepping [e.g., 12], reducing the coupling between the mass balance equations of different components by improving, or changing the numerical scheme [e.g., 32, 41-43], the use of a multi-scale approach [e.g., 28, 38].

While the chosen size of the model domain and the corresponding spatial resolution of the computational grid have only minor influence on the calculated volume fractions of biofilm and precipitated calcite, and thus on the change in porosity and permeability, this does not hold true for the predicted pressures. This study has shown that the absolute values of pressure due to the injections are strongly influenced by the pressure boundary condition. The mathematical solution for the pressure in systems of low compressibility behaves approximately elliptic; thus, pressure signals travel extremely fast and constant values of pressure at Dirichlet boundaries always limit it. Such effects are also discussed, e.g., by $[6,66]$ for $\mathrm{CO}_{2}$ storage in deep saline aquifers. Accordingly, the spatial scale of the pressure footprint due to injection is typically much larger than the spatial scale of the induced reactive transport during MICP, which is the area of focus during sealing. The computationally expensive MICP model usually limits the size of the problem. However, it could be beneficial to employ a multi-physics approach, e.g., by coupling the near-well region with MICP to an outer far-field region where only the hydraulics are modeled with a flow model. Or one could apply an analytical solution, similar to the 
multi-physics approach of, e.g., [20, 21] or the mortar-space upscaling by e.g. [57].

\subsection{Future applications and plans for further model improvement}

Research on MICP and related applications is continuing in our work groups, now focusing primarily on field-scale sealing of near-well-bore delaminations, fractures, voids, and other unrestricted flow channels through well-bore cement. These preferential flow paths can result in lost zonal isolation leading to deleterious flow of fluids between zones or to the surface with multiple potential negative impacts including loss of resource production, reduction of sweep efficiency in EOR operations, and regulatory non-compliance. Our next steps planned are to model wellbore cement sealing related to unconventional oil and gas recovery and $\mathrm{CO}_{2}$ sequestration for projects which are currently underway.

For those applications, several further improvements of the model are crucial. First, the computational efficiency of the model should be increased whenever possible to enable the use of larger simulation domains or more refined grids. Also a larger number of simulation runs, in the context of analyses of scenarios, parameter sensitivities, and uncertainties, is important on the field scale to address the inherent uncertainty related to the lack of information and data at the field scale. Second, the model should be thoroughly validated and, if necessary, re-calibrated to well-controlled, large-scale, full 3D, radial flow experiments to investigate the apparent scale dependence of some model parameters. In particular, it should be investigated why the best-fit parameters for the quasi-1D sand column setups seem to underestimate the precipitation of calcite in 3D radial setups in sandstone. Third, the impact of MICP on the two-phase flow properties needs to be included into the model, as the mentioned common feature of the application is the potential presence of two fluid phases, where relative permeabilities and capillary pressures are essential to have for reliable description of flow. Fourth, the model should also be able to predict the increase in mechanical strength due to MICP, which has been shown in experiments, and could be used to increase the stability of cap rocks.

Data availability The numerical simulator $\operatorname{DuMu}^{\mathrm{X}}$ used in this study can be obtained at http://www.dumux.org/download. php. The specific code used is available at https://git. iws.uni-stuttgart.de/dumux-pub/hommel2018a for the 2018 simulations and https://git.iws.uni-stuttgart.de/dumux-pub/ Shigorina2014a for the 2014 simulations.
Funding information The International Research Training Group NUPUS, funded by the German Research Foundation (DFG), is acknowledged for enabling the model development through funding between 2007 and 2016. Further, we acknowledge the DFG for funding ongoing research related to this study in the grants HO6055/11 and within the Collaborative Research Center 1313. Funding for the laboratory and field MICP experimental work was provided by two US Department of Energy grants DE-FE0004478, "Advanced CO2 Leakage Mitigation using Engineered Biomineralization Sealing Technologies" and DE-FE000959, "Field Test and Evaluation of Engineered Biomineralization Technology for Sealing Existing Wells" with matching support from Southern Company Generation and Shell International Exploration and Production B.V. Additional financial support was also provided by DOE DE-FG02-13ER86571 and NSF award no. DMS0934696. Any opinions, findings, conclusions, or recommendations expressed herein are those of the authors and do not necessarily reflect the views of the Department of Energy (DOE).

Publisher's Note Springer Nature remains neutral with regard to jurisdictional claims in published maps and institutional affiliations.

\section{Appendix}

This appendix provides the reactive source and sink terms in the model for MICP used in this study. In the following tables, we refer to the components (water (w), inorganic carbon (ic), sodium $(\mathrm{Na})$, chloride $(\mathrm{Cl})$, calcium $(\mathrm{Ca})$, urea (u), ammonium/ammonia (a), substrate (s), oxygen $\left(\mathrm{O}_{2}\right)$, and suspended biomass(sb)) and solid phase (biofilm (b) and calcite (c)) with the respective super- or subscripts.

Sodium and chloride do not take part in any of the reactions directly, which is why $q^{\mathrm{Na}}=q^{\mathrm{Cl}}=0$. However, they represent the effect of the presence of ions in the aqueous phase on the fluid properties density and viscosity according to the salinity dependent relations given in [5] and on the activity coefficients of the reacting components calculated using Pitzer equations according to [14, 48, 79], as discussed in detail in [19]. Also calcium is considered to contribute to salinity and ionic strength. All ions are considered in the charge balance used to determine the $\mathrm{pH}$ and the dissociation of total inorganic carbon and ammonia/ammonium.

Table 2 gives all reactive source and sink terms composed of the rates kinetics of the biogeochemical reactions considered in the model. The parameters used to calculated the source and sink terms and rate kinetics are the following (see also Table 3 for their values): $M^{\kappa}$ is the molar mass of $\kappa, Y$ the growth yield coefficient, $F$ the ratio of oxygen to substrate used for growth, $k_{\text {urease }}$ the maximum activity of urease, $k_{\mathrm{ub}}$ the mass ratio of urease to biofilm, $\rho_{\mathrm{b}}$ the density of biofilm, $m^{\kappa}$ the molality of $\kappa$ calculated from the mole fraction $x_{\mathrm{w}}^{\kappa}$ and the water-phase properties, $K_{\mathrm{u}}$ 
Table 2 Component-specific reactive source and sink terms of the model used in this study

\begin{tabular}{|c|c|c|c|}
\hline Component & Source term & & Rates \\
\hline Water & $q^{\mathrm{w}}$ & $=$ & 0 \\
\hline Inorganic carbon & $q^{\text {ic }}$ & $=$ & $r_{\text {diss }}-r_{\text {prec }}+r_{\text {urea }}$ \\
\hline Sodium & $q^{\mathrm{Na}}$ & $=$ & 0 \\
\hline Chloride & $q^{\mathrm{Cl}}$ & $=$ & 0 \\
\hline Calcium & $q^{\mathrm{Ca}}$ & $=$ & $r_{\text {diss }}-r_{\text {prec }}$ \\
\hline Urea & $q^{\mathrm{u}}$ & $=$ & $-r_{\text {urea }}$ \\
\hline Ammonia/ammonium & $q^{\mathrm{a}}$ & $=$ & $2 r_{\text {urea }}$ \\
\hline Substrate & $q^{\mathrm{s}}$ & $=$ & $-\frac{r_{\mathrm{g}}^{\mathrm{sb}}+r_{\mathrm{g}}^{\mathrm{b}}}{M^{\mathrm{s} Y}}$ \\
\hline Oxygen & $q^{\mathrm{O}_{2}}$ & $=$ & $-F \frac{r_{\mathrm{g}}^{\mathrm{sb}}+r_{\mathrm{g}}^{\mathrm{b}}}{M^{\mathrm{O}_{2} Y}}$ \\
\hline Suspended biomass & $q^{\mathrm{sb}}$ & $=$ & $\frac{r_{\mathrm{g}}^{\mathrm{sb}}-r_{\mathrm{b}}^{\mathrm{sb}}-r_{\mathrm{a}}+r_{\mathrm{d}}}{M^{\mathrm{sb}}}$ \\
\hline Biofilm & $q^{\mathrm{b}}$ & $=$ & $\frac{r_{\mathrm{g}}^{\mathrm{b}}-r_{\mathrm{b}}^{\mathrm{b}}+r_{\mathrm{a}}-r_{\mathrm{d}}}{M^{\mathrm{b}}}$ \\
\hline Calcite & $q^{\mathrm{c}}$ & $=$ & $r_{\text {prec }}-r_{\text {diss }}$ \\
\hline Ureolysis rate & $r_{\text {urea }}$ & $=$ & $k_{\text {urease }} k_{\mathrm{ub}} \rho_{\mathrm{b}} \phi_{\mathrm{b}} \frac{m^{\mathrm{u}}}{K_{\mathrm{u}}+m^{\mathrm{u}}}$ \\
\hline Precipitation rate of calcite & $r_{\text {prec }}$ & $=$ & $k_{\text {prec }} A_{\text {sw }}(\Omega-1)^{n_{\text {prec }}} ; \Omega \geq 1$ \\
\hline Dissolution rate of calcite & $r_{\text {diss }}$ & $=$ & $\left(k_{\mathrm{diss}, 1} m_{\mathrm{H}^{+}}+k_{\mathrm{diss}, 2}\right) A_{\mathrm{cw}}(\Omega-1)^{n_{\mathrm{diss}}} ; \Omega<1$ \\
\hline Interfacial area solid and water & $A_{\mathrm{sw}}$ & $=$ & $A_{\mathrm{sw}, 0}\left(1-\frac{\phi_{\mathrm{c}}}{\phi_{0}}\right)^{\frac{2}{3}}$ \\
\hline Interfacial area calcite and water & $A_{\mathrm{cw}}$ & $=$ & $\min \left(A_{\mathrm{sw}}, a_{\mathrm{c}} \phi_{\mathrm{c}}\right)$ \\
\hline Saturation state of calcite & $\Omega$ & $=$ & $\frac{m^{\mathrm{Ca}^{2+}} \gamma_{\mathrm{Ca}^{2+}} m^{\mathrm{CO}_{3}^{2-}} \gamma_{\mathrm{CO}_{3}^{2-}}}{K_{\mathrm{sp}}}$ \\
\hline Growth rate of biofilm & $r_{\mathrm{g}}^{\mathrm{b}}$ & $=$ & $\mu_{\mathrm{g}} \phi_{\mathrm{b}} \rho_{\mathrm{b}}$ \\
\hline Growth rate of suspended biomass & $r_{\mathrm{g}}^{\mathrm{sb}}$ & $=$ & $\mu_{\mathrm{g}} C_{\mathrm{w}}^{\mathrm{sb}} S_{\mathrm{w}} \phi$ \\
\hline Specific growth rate & $\mu_{\mathrm{g}}$ & $=$ & $k_{\mu} Y \frac{C_{\mathrm{w}}^{\mathrm{s}}}{K_{\mathrm{s}}+C_{\mathrm{w}}^{\mathrm{s}}} \frac{C_{\mathrm{w}}^{\mathrm{O}_{2}}}{K_{\mathrm{O}_{2}}+C_{\mathrm{w}}^{\mathrm{O}_{2}}}$ \\
\hline Decay rate of biofilm & $r_{\mathrm{b}}^{\mathrm{b}}$ & $=$ & $\left(b_{0}+\frac{r_{\mathrm{prec}} M^{\mathrm{CaCO}_{3}}}{\rho_{\mathrm{c}}\left(\phi+\phi_{\mathrm{b}}\right)}\right) \phi_{\mathrm{b}} \rho_{\mathrm{b}}$ \\
\hline Decay rate of suspended biomass & $r_{\mathrm{b}}^{\mathrm{sb}}$ & $=$ & $b_{0}\left(1+\frac{K_{\mathrm{pH}}}{\left(m^{\mathrm{H}^{+}}\right)^{2}}\right) C_{\mathrm{w}}^{\mathrm{sb}} S_{\mathrm{w}} \phi$ \\
\hline Attachment rate of biomass & $r_{\mathrm{a}}$ & $=$ & $\left(c_{\mathrm{a}, 1}+c_{\mathrm{a}, 2} \phi_{\mathrm{b}}\right) C_{\mathrm{w}}^{\mathrm{sb}} S_{\mathrm{w}} \phi$ \\
\hline Detachment rate of biomass & $r_{\mathrm{d}}$ & $=$ & $\left(c_{\mathrm{d}}\left(\phi S_{\mathrm{w}}\left|\nabla p_{\mathrm{w}}-\rho_{\mathrm{w}} \mathbf{g}\right|\right)^{0.58}+\frac{\phi_{\mathrm{b}}}{\phi_{0}-\phi_{\mathrm{c}}} \mu_{\mathrm{g}}\right) \phi_{\mathrm{b}} \rho_{\mathrm{b}}$ \\
\hline
\end{tabular}

For details, see [34] and [19]. The parameters values are given in Table 3 the half-saturation coefficients for ureolysis, $k_{\text {prec }}$ and $n_{\text {prec }}$ are empirical precipitation parameters, $k_{\mathrm{diss}, 1}, k_{\mathrm{diss}, 2}$, and $n_{\text {diss }}$ are dissolution parameters, $A_{\mathrm{sw}, 0}$ the initial interfacial area of solid and water phase, $a_{\mathrm{c}}$ the specific surface area of calcite, $K_{\mathrm{sp}}$ the calcite solubility product and $\gamma_{\kappa}$ the activity coefficients of $\kappa$ calculated using Pitzer equations $[14,48,79] k_{\mu}$ the maximum specific growth rate, $C_{\mathrm{w}}^{\mathrm{s}}$ and $C_{\mathrm{w}}^{\mathrm{O}_{2}}$ the mass concentrations of substrate and oxygen, calculated from the mole fraction $x_{\mathrm{w}}^{\kappa}$ and the water-phase properties, $K_{\mathrm{S}}$ and $K_{\mathrm{O}_{2}}$ the half-saturation coefficients for substrate and oxygen, respectively, $b_{0}$ is the endogenous decay rate, $K_{\mathrm{pH}}$ an empirical constant accounting for increased bacterial inactivation at non-optimal $\mathrm{pH}, c_{\mathrm{a}, 1}$ a general first-order attachment coefficient, $c_{\mathrm{a}, 2}$ a attachment coefficient for preferential attachment to existing biofilm, $c_{\mathrm{d}}$ the first order coefficient for detachment due to shear stress, and $\left|\nabla p_{\mathrm{w}}-\rho_{\mathrm{w}} \mathbf{g}\right|$ the absolute value of the potential gradient. 
Table 3 Parameter values used for the simulations in 2014 and 2018

\begin{tabular}{|c|c|c|c|}
\hline Param. & Unit & Value & Reference \\
\hline$\rho_{\mathrm{c}}$ & $\mathrm{kg} / \mathrm{m}^{3}$ & 2710 & [19] \\
\hline$\rho_{\mathrm{b}}$ & $\mathrm{kg} / \mathrm{m}^{3}$ & $10 / 6.9$ & {$[19] /[34]$} \\
\hline$D_{\mathrm{w}}^{\kappa}$ & $\mathrm{m}^{2} / \mathrm{s}$ & $1.587 \times 10^{-9}$ & {$[65]$} \\
\hline$\alpha_{1}$ & $\mathrm{~m}$ & 0.025 & {$[26]$} \\
\hline$A_{\mathrm{sw}, 0}$ & $\mathrm{~m}^{2} / \mathrm{m}^{3}$ & 5000 & [19] \\
\hline$a_{\mathrm{c}}$ & $\mathrm{m}^{2} / \mathrm{m}^{3}$ & 20000 & [19] \\
\hline$k_{\text {prec }}$ & $\mathrm{mol} / \mathrm{m}^{2} \mathrm{~s}$ & $1.5 \times 10^{-10}$ & {$[83]$} \\
\hline$n_{\text {prec }}$ & - & 3.27 & {$[83]$} \\
\hline$k_{\mathrm{diss}, 1}$ & $\mathrm{~kg}_{\mathrm{H}_{2} \mathrm{O} / \mathrm{m}^{2} \mathrm{~s}}$ & $8.9 \times 10^{-1}$ & {$[13]$} \\
\hline$k_{\text {diss }, 2}$ & $\mathrm{~mol} / \mathrm{m}^{2} \mathrm{~s}$ & $6.5 \times 10^{-7}$ & {$[13]$} \\
\hline$n_{\text {diss }}$ & - & 1 & {$[25]$} \\
\hline$k_{\mu}$ & $1 / \mathrm{s}$ & $4.1667 \times 10^{-5}$ & {$[15]$} \\
\hline$K_{\mathrm{s}}$ & $\mathrm{kg} / \mathrm{m}^{3}$ & $7.99 \times 10^{-4}$ & {$[68]$} \\
\hline$K_{\mathrm{O}_{2}}$ & $\mathrm{~kg} / \mathrm{m}^{3}$ & $2 \times 10^{-5}$ & {$[29]$} \\
\hline$Y$ & - & 0.5 & {$[67]$} \\
\hline$F$ & - & 0.5 & {$[47]$} \\
\hline$b_{0}$ & $1 / \mathrm{s}$ & $3.18 \times 10^{-7}$ & {$[68]$} \\
\hline$K_{\mathrm{pH}}$ & $\mathrm{mol}^{2} / \mathrm{kg}_{\mathrm{H}_{2} \mathrm{O}}^{2}$ & $6.15 \times 10^{-10}$ & [39] \\
\hline$c_{\mathrm{a}, 1}$ & $1 / \mathrm{s}$ & $1.5 \times 10^{-5} / 8.3753 \times 10^{-8}$ & Estimated / [34] \\
\hline$c_{\mathrm{a}, 2}$ & $1 / \mathrm{s}$ & $5 \times 10^{-6} / 8.5114 \times 10^{-7}$ & Estimated / [34] \\
\hline$c_{\mathrm{d}}$ & $1 / \mathrm{s}$ & $2.89 \times 10^{-8}$ & {$[18]$} \\
\hline$k_{\text {urease }}$ & $\mathrm{mol} / \mathrm{kgs}$ & 706.7 & {$[45]$} \\
\hline$K_{\mathrm{u}}$ & $\mathrm{mol} / \mathrm{kg}_{\mathrm{H}_{2} \mathrm{O}}$ & 0.355 & {$[45]$} \\
\hline$k_{\mathrm{ub}}$ & - & $1 \times 10^{-2} / 3.81 \times 10^{-4}$ & {$[1] /[34]$} \\
\hline
\end{tabular}

In general, for both sets of simulations, the parameter values as published in [34] were used. However, as the recalibration of the model was not finished during the 2014 simulations, the fitting parameters were different and given in the table in the format parameter 2014/parameter 2018. These parameters are compared in detail in Table 1

\section{References}

1. Bachmeier, K.L., Williams, A.E., Warmington, J.R., Bang, S.S.: Urease activity in microbiologically-induced calcite precipitation. J. Biotechnol. 93(2), 171-81 (2002)

2. Barkouki, T.H., Martinez, B.C., Mortensen, B.M., Weathers, T.S., De Jong, J.D., Ginn, T.R., Spycher, N.F., Smith, R.W., Fujita, Y.: Forward and inverse bio-geochemical modeling of microbially induced calcite precipitation in half-meter column experiments. Transp. Porous Media 90(1), 23-39 (2011). https://doi.org/10.1007/s11242-011-9804-Z

3. Bastian, P., Blatt, M., Dedner, A., Engwer, C., Klöfkorn, R., Kornhuber, R., Ohlberger, M., Sander, O.: A generic grid interface for parallel and adaptive scientific computing Part II: Implementation and tests in DUNE. Comput. (Vienna/New York) 82(2-3), 121-138 (2008a). https://doi.org/10.1007/s00607-008-0004-9

4. Bastian, P., Blatt, M., Dedner, A., Engwer C., Klöfkorn, R., Ohlberger, M., Sander, O.: A generic grid interface for parallel and adaptive scientific computing. Part I: Abstract framework. Comput. (Vienna/New York) 82(2-3), 103-119 (2008b). https://doi.org/10.1007/s00607-008-0003-x
5. Batzle, M., Wang, Z.: Seismic Properties of Pore Fluids. Geophysics 57(11), 1396-1408 (1992). https://doi.org/10.1190/1. 1443207

6. Birkhölzer, J.T., Zhou, Q., Tsang, C.F.: Large-scale impact of $\mathrm{CO}_{2}$ storage in deep saline aquifers: A sensitivity study on pressure response in stratified systems. Int. J. Greenh. Gas Control 3(2), 181-194 (2009)

7. Bottero, S., Picioreanu, C., Enzien, M.V., Van Loosdrecht, M., Bruining, J., Heimovaara, T.: Formation Damage and Impact on Gas Flow Caused by Biofilms Growing Within Proppant Packing Used in Hydraulic Fracturing. Society of Petroleum Engineers, https://doi.org/10.2118/128066-MS (2010)

8. Bottero, S., Storck, T., Heimovaara, T.J., van Loosdrecht, M.C., Enzien, M.V., Picioreanu, C.: Biofilm development and the dynamics of preferential flow paths in porous media. Biofouling 29(9), 1069-1086 (2013). https://doi.org/10.1080/08927014. 2013.828284

9. Bringedal, C., Berre, I., Pop, I.S., Radu, F.A.: Upscaling of Non-isothermal Reactive Porous Media Flow with Changing Porosity. Transp. Porous Media 114(2), 371-393 (2016). https://doi.org/10.1007/s11242-015-0530-9

10. Burbank, M.B., Weaver, T.J., Green, T.L., Williams, B.C., Crawford, R.L.: Precipitation of calcite by indigenous microorganisms to strengthen liquefiable soils. Geomicrobiol J. 28(4), 301-312 (2011). https://doi.org/10.1080/01490451.2010.499929

11. Burr, D.T., Sudicky, E.A., Naff, R.L.: Nonreactive and reactive solute transport in three-dimensional heterogeneous porous media: Mean displacement, plume spreading, and uncertainty. Water Resour. Res. 30(3), 791-815 (1994). https://doi.org/10. 1029/93WR02946

12. Carrayrou, J., Hoffmann, J., Knabner, P., Kräutle, S., de Dieuleveult, C., Erhel, J., Van der Lee, J., Lagneau, V., Mayer, K.U., MacQuarrie, K.T.B.: Comparison of numerical methods for simulating strongly nonlinear and heterogeneous reactive transport problems?the MoMaS benchmark case. Comput. Geosci. 14(3), 483-502 (2010). https://doi.org/10.1007/s10596-010-9178-2

13. Chou, L., Garrels, R.M., Wollast, R.: Comparative study of the kinetics and mechanisms of dissolution of carbonate minerals. Chem. Geol. 78, 269-282 (1989)

14. Clegg, S.L., Whitfield, M.: A chemical model of seawater including dissolved ammonia and the stoichiometric dissociation constant of ammonia in estuarine water and seawater from -2 to $40^{\circ}$ c. Geochim. Cosmochim. Acta 59(12), 2403-2421 (1995)

15. Connolly, J.M., Kaufman, M., Rothman, A., Gupta, R., Redden, G., Schuster, M., Colwell, F., Gerlach, R.: Construction of two ureolytic model organisms for the study of microbially induced calcium carbonate precipitation. J. Microbiol. Methods 94(3), 290-299 (2013). https://doi.org/10.1016/j.mimet.2013.06.028

16. Cunningham, A.B., Phillips, A.J., Troyer, E., Lauchnor, E.G., Hiebert, R., Gerlach, R., Spangler, L.H.: Wellbore leakage mitigation using engineered biomineralization. Energy Procedia 63, 4612-4619 (2014). https://doi.org/10.1016/j.egypro.2014.11.494

17. Cuthbert, M.O., McMillan, L.A., Handley-Sidhu, S., Riley, M.S., Tobler, D.J., Phoenix, V.R.: A field and modeling study of fractured rock permeability reduction using microbially induced calcite precipitation. Environ. Sci. Technol. 47(23), 13637-13643 (2013). https://doi.org/10.1021/es402601g

18. Ebigbo, A., Helmig, R., Cunningham, A.B., Class, H., Gerlach, R.: Modelling biofilm growth in the presence of carbon dioxide and water flow in the subsurface. Adv. Water Resour. 33(7), 762-781 (2010). https://doi.org/10.1016/j.advwatres.2010.04.004

19. Ebigbo, A., Phillips, A.J., Gerlach, R., Helmig, R., Cunningham, A.B., Class, H., Spangler, L.H.: Darcy-scale modeling of microbially induced carbonate mineral precipitation in sand columns. Water Resour. Res. 48(7), W07519 (2012). https://doi.org/10.1029/2011WR011714 
20. Faigle, B., Helmig, R., Aavatsmark, I., Flemisch, B.: Efficient multiphysics modelling with adaptive grid refinement using a MPFA method. Comput. Geosci. 18(5), 625-636. https://doi.org/10.1007/s10596-014-9407-1 (2014)

21. Faigle, B., Elfeel, M.A., Helmig, R., Becker, B., Flemisch, B., Geiger, S.: Multi-physics modeling of non-isothermal compositional flow on adaptive grids. Comput. Methods Appl. Mech. Eng. 292, 16-34 (2015). https://doi.org/10.1016/j.cma.2014.11.030

22. Ferris, F.G., Stehmeier, L.G., Kantzas, A., Mourits, F.M.: Bacteriogenic mineral plugging. J. Can. Pet. Technol. 35(8), 5661 (1996). https://doi.org/10.2118/96-08-06

23. Fidaleo, M., Lavecchia, R.: Kinetic study of enzymatic urea hydrolysis in the $\mathrm{pH}$ range 4-9. Chem. Biochem. Eng. Q. 17, 311-318 (2003)

24. Flemisch, B., Darcis, M., Erbertseder, K., Faigle, B., Lauser, A., Mosthaf, K., Müthing, S., Nuske, P., Tatomir, A., Wolff, M., Helmig, R.: Dumu ${ }^{X}$ : DUNE for multi-\{phase,component,scale,physics,...\} flow and transport in porous media. Adv. Water Resour. 34(9), 1102-1112 (2011). https://doi.org/10.1016/j. advwatres.2011.03.007

25. Flukiger, F., Bernard, D.: A new numerical model for pore scale dissolution of calcite due to $\mathrm{CO}_{2}$ saturated water flow in 3D realistic geometry: Principles and first results. Chem. Geol. 265(1-2), 171-180 (2009). https://doi.org/10.1016/j.chemgeo.2009.05.004

26. Frippiat, C.C., Pérez, P.C., Holeyman, A.E.: Estimation of laboratory-scale dispersivities using an annulus-and-core device. J. Hydrol. 362(1-2), 57-68 (2008). https://doi.org/10.1016/j. jhydrol.2008.08.007

27. Fujita, Y., Taylor, J.L., Gresham, T.L.T., Delwiche, M.E., Colwell, F.S., McLing, T.L., Petzke, L.M., Smith, R.W.: Stimulation of microbial urea hydrolysis in groundwater to enhance calcite precipitation. Environ. Sci. Technol. 42(8), 3025-3032 (2008)

28. Hajibeygi, H., Bonfigli, G., Hesse, M.A., Jenny, P.: Iterative multiscale finite-volume method. J. Comput. Phys. 227(19), 8604-8621 (2008). https://doi.org/10.1016/j.jcp.2008.06.013

29. Hao, O.J., Richard, M.G., Jenkins, D., Blanch, H.W.: The halfsaturation coefficient for dissolved oxygen: a dynamic method for its determination and its effect on dual species competition. Biotechnol. Bioeng. 25(2), 403-16 (1983). https://doi.org/10. 1002/bit.260250209

30. Helmig, R.: Multiphase Flow and Transport Processes in the Subsurface - A Contribution to the Modeling of Hydrosystems. Springer, Berlin (1997)

31. Heße, F., Radu, F., Thullner, M., Attinger, S.: Upscaling of the advection-diffusion-reaction equation with Monod reaction. Adv. Water Resour. 32(8), 1336-1351 (2009). https://doi.org/10.1016/j. advwatres.2009.05.009

32. Hoffmann, J., Kräutle, S., Knabner, P.: A general reduction scheme for reactive transport in porous media. Comput. Geosci. 16(4), 1081-1099 (2012). https://doi.org/10.1007/s10596-0129304-4

33. Hommel, J., Cunningham, A.B., Helmig, R., Ebigbo, A., Class, H.: Numerical investigation of microbially induced calcite precipitation as a leakage mitigation technology. Energy Procedia 40C, 392-397 (2013). https://doi.org/10.1016/j.egypro.2013.08.045

34. Hommel, J., Lauchnor, E.G., Phillips, A.J., Gerlach, R., Cunningham, A.B., Helmig, R., Ebigbo, A., Class, H.: A revised model for microbially induced calcite precipitation: Improvements and new insights based on recent experiments. Water Resour. Res. 51(5), 3695-3715 (2015). https://doi.org/10.1002/2014WR016503

35. Hommel, J., Lauchnor, E.G., Gerlach, R., Cunningham, A.B., Ebigbo, A., Helmig, R., Class, H.: Investigating the influence of the initial biomass distribution and injection strategies on BiofilmMediated calcite precipitation in porous media. Transp. Porous Media 114(2), 557-579 (2016). https://doi.org/10.1007/s11242015-0617-3
36. Hommel, J., Coltman, E., Class, H.: Porosity-Permeability Relations for Evolving Pore Space: A Review with a Focus on (Bio-)geochemically Altered Porous Media. Transport in Porous Media, https://doi.org/10.1007/s11242-018-1086-2 (2018)

37. Jacques, D., Šimúnek, J., Mallants, D., van Genuchten, M.: Modelling coupled water flow, solute transport and geochemical reactions affecting heavy metal migration in a podzol soil. Geoderma 145(3), 449-461 (2008). https://doi.org/10.1016/j. geoderma.2008.01.009

38. Jenny, P., Lee, S., Tchelepi, H.: Adaptive Multiscale finiteVolume Method for Multiphase Flow and Transport in Porous Media. Multiscale Model. Simul. 3(1), 50-64 (2005). https://doi.org/10.1137/030600795

39. Kim, D.S., Thomas, S., Fogler, H.S.: Effects of $\mathrm{pH}$ and trace minerals on long-term starvation of Leuconostoc mesenteroides. Appl. Environ. Microbiol. 66(3), 976-81 (2000)

40. Krajewska B.: Urease-aided calcium carbonate mineralization for engineering applications: A review. Journal of Advanced Research, https://doi.org/10.1016/j.jare.2017.10.009 (2017)

41. Kräutle, S., Knabner, P.: A new numerical reduction scheme for fully coupled multicomponent transport-reaction problems in porous media. Water Resour. Res. 41(9), W09414 (2005). https://doi.org/10.1029/2004WR003624

42. Kräutle, S., Knabner, P.: A reduction scheme for coupled multicomponent transport-reaction problems in porous media: Generalization to problems with heterogeneous equilibrium reactions. Water Resour. Res. 43(3), W03429 (2007). https://doi.org/10.1029/2005WR004465

43. Kumar, K., van Noorden, T., Pop, I.: Effective dispersion equations for reactive flows involving free boundaries at the microscale. Multiscale Model. Simul. 9(1), 29-58 (2011). https://doi.org/10.1137/100804553

44. Landa-Marbán, D., Radu, F.A., Nordbotten, J.M.: Modeling and simulation of microbial enhanced oil recovery including interfacial area. Transp. Porous Media 120(2), 395-413 (2017). https://doi.org/10.1007/s11242-017-0929-6

45. Lauchnor, E.G., Topp, D.M., Parker, A.E., Gerlach, R.: Whole cell kinetics of ureolysis by Sporosarcina pasteurii. J. Appl. Microbiol. 118(6), 1321-1332 (2015). https://doi.org/10.1111/jam.12804

46. Martinez, B., De Jong, J.T., Ginn, T.R.: Bio-geochemical reactive transport modeling of microbial induced calcite precipitation to predict the treatment of sand in one-dimensional flow. Comput. Geotech. 58, 1-13 (2014). https://doi.org/10.1016/j.compgeo. 2014.01.013

47. Mateles, R.I.: Calculation of the oxygen required for cell production. Biotechnol. Bioeng. 13(4), 581-582 (1971). https://doi.org/ 10.1002/bit.260130411

48. Millero, F.J., Milne, P.J., Thurmond, V.L.: The solubility of calcite, strontianite and witherite in $\mathrm{NaCl}$ solutions at $25^{\circ} \mathrm{c}$. Geochim. Cosmochim. Acta 48, 1141-1143 (1984). https://doi.org/10.1016/ 0016-7037(84)90205-9

49. Minto, J.M., Tan, Q., Lunn, R.J., Mountassir, G.E., Guo, H., Cheng, X.: 'Microbial mortar'-restoration of degraded marble structures with microbially induced carbonate precipitation. Constr. Build. Mater. 180, 44-54 (2018). https://doi.org/10.1016/j. conbuildmat.2018.05.200

50. Mitchell, A.C., Phillips, A.J., Schultz, L., Parks, S., Spangler, L.H., Cunningham, A.B., Gerlach, R.: Microbial $\mathrm{CaCO}_{3}$ mineral formation and stability in an experimentally simulated high pressure saline aquifer with supercritical $\mathrm{CO}_{2}$. Int. J. Greenh. Gas Control 15, 86-96 (2013). https://doi.org/10.1016/j.ijggc.2013. 02.001

51. Nassar, M.K., Gurung, D., Bastani, M., Ginn, T.R., Shafei, B., Gomez, M.G., Graddy, C.M.R., Nelson, D.C., DeJong, J.T.: Large-Scale Experiments in microbially induced calcite precipitation (MICP): Reactive transport model develop- 
ment and prediction. Water Resour. Res. 54, 480-500 (2018). https://doi.org/10.1002/2017WR021488

52. Nemati, M., Voordouw, G.: Modification of porous media permeability, using calcium carbonate produced enzymatically in situ. Enzyme Microb. Technol. 33(5), 635-642 (2003). https://doi.org/10.1016/S0141-0229(03)00191-1

53. Nielsen, S.M., Nesterov, I., Shapiro, A.A.: Simulations of microbial-enhanced oil recovery: Adsorption and filtration. Transp. Porous Media 102(2), 227-259 (2014). https://doi.org/10. 1007/s11242-014-0273-Z

54. Nielsen, S.M., Nesterov, I., Shapiro, A.A.: Microbial enhanced oil recovery-a modeling study of the potential of sporeforming bacteria. Comput. Geosci. 20(3), 567-580 (2016). https://doi.org/10.1007/s10596-015-9526-3

55. van Noorden, T.L., Pop, I.S., Ebigbo, A., Helmig, R.: An upscaled model for biofilm growth in a thin strip. Water Resour. Res. 46(6), W06505 (2010). https://doi.org/10.1029/2009WR008217

56. van Paassen, L.A., Ghose, R., van der Linden, T.J.M., van der Star, W.R.L., van Loosdrecht, M.C.M.: Quantifying Biomediated Ground Improvement by Ureolysis: Large-Scale Biogrout Experiment. J. Geotechn. Geoenviron. Eng. 136(12), 1721-1728 (2010). https://doi.org/10.1061/(ASCE)GT.1943-5606.0000382

57. Peszyńska, M., Wheeler, M.F., Yotov, I.: Mortar Upscaling for Multiphase Flow in Porous Media. Comput. Geosci. 6(1), 73-100 (2002). https://doi.org/10.1023/A:1016529113809

58. Peszyniska, M., Trykozko, A., Iltis, G., Schlueter, S., Wildenschild, D.: Biofilm growth in porous media: experiments, computational modeling at the porescale, and upscaling. Adv. Water Resour. 95, 288-301 (2016). https://doi.org/10.1016/j.advwatres.2015.07.008

59. Phillips, A.J., Gerlach, R., Lauchnor, E.G., Mitchell, A.C., Cunningham, A.B., Spangler, L.H.: Engineered applications of ureolytic biomineralization: a review. Biofouling 29(6), 715-733 (2013a). https://doi.org/10.1080/08927014.2013.796550

60. Phillips, A.J., Lauchnor, E.G., Eldring, J.J., Esposito, R., Mitchell, A.C., Gerlach, R., Cunningham, A.B., Spangler, L.H.: Potential $\mathrm{CO}_{2}$ leakage reduction through biofilm-induced calcium carbonate precipitation. Environ. Sci. Technol. 47, 142-149 (2013b). https://doi.org/10.1021/es301294q

61. Phillips, A.J., Eldring, J., Hiebert, R., Lauchnor, E.G., Mitchell, A.C., Cunningham, A.B., Spangler, L.H., Gerlach, R.: Design of a meso-scale high pressure vessel for the laboratory examination of biogeochemical subsurface processes. J. Pet. Sci. Eng. 126, 55-62 (2015). https://doi.org/10.1016/j.petrol.2014.12.008

62. Phillips, A.J., Cunningham, A.B., Gerlach, R., Hiebert, R., Hwang, C., Lomans, B.P., Westrich, J., Mantilla, C., Kirksey, J., Esposito, R., Spangler, L.H.: Fracture sealing with MicrobiallyInduced calcium carbonate precipitation: a field study. Environ. Sci. Technol. 50, 4111-4117 (2016). https://doi.org/10.1021/acs. est.5b05559

63. Prommer, H., Grassi, M.E., Davis, A.C., Patterson, B.M.: Modeling of microbial dynamics and geochemical changes in a metal bioprecipitation experiment. Environ. Sci. Technol. 41(24), 8433-8438 (2007). https://doi.org/10.1021/es071123n

64. Qin, C., Hassanizadeh, S.M., Ebigbo, A.: Pore-scale network modeling of microbially induced calcium carbonate precipitation: Insight into scale dependence of biogeochemical reaction rates. Water Resour. Res. 52(11), 8794-8810 (2016). https://doi.org/10.1002/2016WR019128

65. Riquelme, R., Lira, I., Pérez-López, C., Rayas, J.A., Rodríguezvera, R.: Interferometric measurement of a diffusion coefficient: comparison of two methods and uncertainty analysis. J. Phys. D: Appl. Phys. 40(9), 2769-2776 (2007). https://doi.org/10.1088/0022-3727/40/9/015

66. Schäfer, F., Walter, L., Class, H., Müller, C.: The regional pressure impact of $\mathrm{CO}_{2}$ storage: a showcase study from the North
German Basin. Environ. Earth Sci. 65(7), 2037-2049 (2012). https://doi.org/10.1007/s12665-011-1184-8

67. Seto, M., Alexander, M.: Effect of bacterial density and substrate concentration on yield coefficients. Appl. Environ. Microbiol. 50(5), 1132-1136 (1985)

68. Taylor, S.W., Jaffé, P.R.: Substrate and biomass transport in a porous-medium. Water Resour. Res. 26(9), 2181-2194 (1990). https://doi.org/10.1029/WR026i009p02181

69. Tebes-Stevens, C., Valocchi, A.J., VanBriesen, J.M., Rittmann, B.E.: Multicomponent transport with coupled geochemical and microbiological reactions: model description and example simulations. J. Hydrol. 209(1), 8-26 (1998). https://doi.org/10.1016/ S0022-1694(98)00104-8

70. Umar, M., Kassim, K.A., Chiet, K.T.P.: Biological process of soil improvement in civil engineering: a review. J. Rock Mechan. Geotechn. Eng. 8(5), 767-774 (2016). https://doi.org/10.1016/j.jrmge.2016.02.004

71. Verma, A., Pruess, K.: Thermohydrological conditions and silica redistribution near high-level nuclear wastes emplaced in saturated geological formations. J. Geophys. Res. Solid Earth 93(B2), 1159-1173 (1988). https://doi.org/10.1029/JB093iB02p01159

72. Vilcáez, J., Li, L., Wu, D., Hubbard, S.S.: Reactive transport modeling of induced selective plugging by leuconostoc mesenteroides in carbonate formations. Geomicrobiol J. 30(9), 813-828 (2013). https://doi.org/10.1080/01490451.2013.774074

73. van der Vorst, H.A.: BI-CGSTAB: A fast and smoothy converging variant of BI-CG for the solution of nansymmetric linear systems. SIAM J. Sci. Comput. 13(2), 631-644 (1992)

74. Watson, I.a., Oswald, S.E., Mayer, K.U., Wu, Y., Banwart, S.a.: Modeling kinetic processes controlling hydrogen and acetate concentrations in an aquifer-derived microcosm. Environ. Sci. Tech. 37(17), 3910-3919 (2003). https://doi.org/10.1021/es020242u

75. Whiffin, V.S., La van, P., Harkes, M.P.: Microbial carbonate precipitation as a soil improvement technique. Geomicrobiol. J. 24(5), 417-423 (2007). https://doi.org/10.1080/0149045070143 6505

76. van Wijngaarden, W.K., Vermolen, F.J., Meurs, G.A.M., Vuik, C.: Modelling Biogrout: A new ground improvement method based on microbial-induced carbonate precipitation. Transp. Porous Media 87(2), 397-420 (2011). https://doi.org/10.1007/s11242010-9691-8

77. van Wijngaarden, W.K., Vermolen, F.J., Meurs, G.A.M., Vuik, C.: A mathematical model for Biogrout. Comput. Geosci. 17(3), 463-478 (2013). https://doi.org/10.1007/s10596-012-9316-0

78. van Wijngaarden, W.K., van Paassen, L.A., Vermolen, F.J., van Meurs, G.A.M., Vuik, C.: A reactive transport model for biogrout compared to experimental data. Transp. Porous Media 111(3), 627-648 (2016). https://doi.org/10.1007/s11242-015-0615-5

79. Wolf, M., Breitkopf, O., Puk, R.: Solubility of calcite in different electrolytes at temperatures between 10 and $60^{\circ} \mathrm{C}$ and at $\mathrm{CO}_{2}$ partial pressures of about $1 \mathrm{kPa}$. Geochem. J. 76, 291-301 (1989)

80. Zhang, T., Klapper, I.: Mathematical model of biofilm induced calcite precipitation. Water Sci. Technol. 61(11), 2957 (2010). https://doi.org/10.2166/wst.2010.064

81. Zhang, T., Klapper, I.: Mathematical model of the effect of electrodiffusion on biomineralization. Int. J. Non-Linear Mech. 46(4), 657-666 (2011). https://doi.org/10.1016/j.ijnonlinmec. 2010.12.008

82. Zhang, T., Klapper, I.: Critical occlusion via biofilm induced calcite precipitation in porous media. J. Phys. 16(5), 055009 (2014). https://doi.org/10.1088/1367-2630/16/5/055009

83. Zhong, S., Mucci, A.: Calcite and aragonite precipitation from seawater solutions of various salinities: Precipitation rates and overgrowth compositions. Chem. Geol. 78, 283-299 (1989) 